Opportunity \&

Inclusive Growth

INSTITUTE

- 7 多

FEDERAL RESERVE BANK OF MINNEAPOLIS

INSTITUTE WORKING PAPER

No. 24

\title{
The Return to Big City Experience: Evidence from Refugees in Denmark
}

Revised November 2020

\section{Fabian Eckert}

University of California, San Diego and

Federal Reserve Bank of Minneapolis

\author{
Mads Hejlesen \\ Aarhus University \\ Conor Walsh \\ Princeton University
}

DOI: https://doi.org/10.21034/iwp.24

Keywords: Agglomeration economies; Urban; Regional labor markets; Resettlement; Wage differentials JEL classification: R11, R12, R23, J31, J61

The views expressed herein are those of the authors and not necessarily those of the Federal Reserve Bank of Minneapolis or the Federal Reserve System. 


\title{
The Return to Big City Experience: Evidence from Refugees in Denmark*
}

\author{
Fabian Eckert ${ }^{\dagger} \quad$ Mads Hejlesen ${ }^{\ddagger} \quad$ Conor Walsh ${ }^{\S}$
}

June 2020

\begin{abstract}
We offer causal evidence of higher returns to experience in big cities. Exploiting a natural experiment that settled refugees across labor markets in Denmark between 1986 and 1998, we find that refugees initially earn similar wages across locations. However, those placed in Copenhagen exhibit 35\% faster wage growth with each additional year of experience. Faster sorting of workers towards the type of establishments, occupations, and industries typically found in cities accounts for the vast majority of this urban wage growth premium.
\end{abstract}

${ }^{*}$ We are indebted to Giuseppe Moscarini and Rune Vejlin for their continued guidance and support with this project. For early readings and comments, we are grateful to Gilles Duranton, Costas Meghir, Peter Schott, and Linh Tô. We also thank Costas Arkolakis, George Borjas, Anna Piil Damm, Ed Glaeser, Anja Grujovic, Philipp Kircher, Samuel Kortum, Thibaut Lamadon, Dávid Nagy, Michael Peters, Stephen Redding, Esteban RossiHansberg, Sharon Traiberman, Fabrizio Zilibotti, and the audience at the NBER Urban SI 2018 for helpful comments. We gratefully acknowledge financial support from the Cowles Foundation, the MacMillan Center at Yale University, and the Dale T. Mortensen Centre at Aarhus University.

†University of California, San Diego, Department of Economics; Email: fpe@ucsd.edu

$\ddagger$ Aarhus University, Department of Economics and Business Economics and the Dale T. Mortensen Centre; E-mail: mhejlesen@econ.au.dk

$\S$ Yale University, Department of Economics; Email: conor.walsh@yale.edu 


\section{INTRODUCTION}

Across countries, average wages are higher in big cities compared to more rural areas, even after controlling for worker level observables. The resulting question of whether bigger cities make workers more productive or whether more productive workers choose to live in bigger cities has occupied economists for a long time. ${ }^{1}$

Leading empirical research on this topic uses worker fixed effects to control for sorting on unobserved ability across locations (Glaeser and Mare (2001); D'Costa and Overman (2014); De La Roca and Puga (2017); Combes, Duranton, and Gobillon (2008)). An important limitation of this approach is that identification relies on individuals who migrate across locations. Selection into moving hence induces a potential source of bias in the resulting estimates, which would also confound any subsequent investigation into the determinants of the city wage premium.

In contrast, this paper uses a natural experiment in Denmark to isolate the causal effect of placement into a big city on workers' lifetime wages and earnings for a particular population and investigates the underlying mechanisms. Between 1986 and 1998, the Danish government assigned 80,000 newly arriving refugees to municipalities across Denmark, without regard to a refugee's labor market-relevant characteristics. ${ }^{2}$ Since refugees

\footnotetext{
${ }^{1}$ While spatial equilibrium requires higher wages in big cities to compensate for higher local prices (c.f. Rosen (1979); Roback (1982); Allen and Arkolakis (2014); Redding (2016)), there must be productive advantages in big cities that allow local firms to pay higher wages in the first place (see Glaeser and Mare (2001)). If not, firms producing tradable goods or services would relocate to save on wages. These advantages can stem either from a more talented pool of labor or features of big cities beyond the worker types they attract. See Ahlfeldt and Pietrostefani (2019) for a recent survey of the empirical literature on the economics of density, and Rosenthal and Strange (2004) and Duranton and Puga (2004) for earlier reviews.

${ }^{2}$ Other papers in economics have used the exogenous variation associated with the Nordic refugee dispersal policies. Edin et al. (2003) exploits a similar policy in Sweden, while Damm and Dustmann (2014) and Dustmann et al. (2019) use the same natural experiment as we do; they all investigate research questions unrelated to ours.
} 
did not choose their location, this natural experiment provides a unique setting to understand the effect of working in big cities on labor market outcomes. For our baseline analysis, we divide Denmark's economy into Copenhagen, the country's capital and only big city, and the union of all remaining small cities and towns. We exploit the quasi-random assignment of refugees across these two zones and examine how labor market outcomes differed between the two groups, both initially and over time.

We first document the treatment effects of assignment to Copenhagen on lifetime wage and earnings paths. In contrast with previous studies, we find that refugees initially earn similar hourly wages across areas. However, individuals settled in Copenhagen see their wages and earnings grow around $35 \%$ faster with every additional year of experience relative to those settled outside Copenhagen. This treatment effect is substantial and comparable in magnitude to the return to an additional two years of education over a working life.

We then discuss the extent to which this treatment effect reflects the true differences in the return to experience between Copenhagen and elsewhere, given that some refugees migrate in the years after assignment. We derive tight bounds on the return to big city experience by comparing refugees who never migrate to those who do. Our estimates imply a difference in the urban wage premium of 17 percentage points between individuals with 0 years of big city experience compared to those with 20. These estimates of the return to big city experience are similar to those reported in the seminal work by Glaeser and Mare (2001). These authors find a 13 percentage point increase in the urban wage premium between individuals with 0 to 5 years experience and those with 21 to 25 years of experience in regressions with and without person fixed effects.

Next, we investigate the mechanisms underlying the return to big city experience. Of course, city size itself can only affect wage growth through its correlation with various labor market characteristics, which in turn affect 
labor market outcomes. We draw on an administrative matched employeremployee data set with detailed information on the universe of workers and establishments in Denmark. We use this information to decompose the big city wage growth premium into contributions from three observable job characteristics: firm type, occupation, and industry. We find that differential sorting towards high-wage, service establishments, occupations, and industries typically found in cities explains the majority of the return to big city experience. Over time, a refugee assigned to Copenhagen is increasingly likely to work at more productive firms and in more skill-intensive occupations and industries than one settled outside Copenhagen. Most previous studies have not taken a stand on the contribution of firm characteristics to the urban wage premium. ${ }^{3}$ Moreover, in explaining our findings, we can rule out several other mechanisms, including separate wage trends between locations, the effects of ethnic enclaves, and regional variation in educational take-up. Our results also suggest that spatial differences in assimilation have no bearing on the differences in the returns to experience we identify. 4

Recent calls for more causal inference in urban economics (Baum-Snow and Ferreira, 2015) have highlighted the need for well-identified estimates of the impact of cities on workers. Such inference often requires tradeoffs between the ability to recover parameters of interest and the setting's generality. While our setting is a particular one, we uncover mechanisms behind the differential return to experience across cities that appear general. In particular, the greater presence of highly productive establishments, high-skill occupations, and service industries is likely to steepen the earnings paths

\footnotetext{
${ }^{3}$ See, for example, Wheeler (2006), Gould (2007), Baum-Snow and Pavan (2012), Papageorgiou (2017), De la Roca et al. (2014), and Grujovic (2018). Notable exceptions are Combes et al. (2012), Mion and Naticchioni (2009), and Dauth et al. (2018). For papers that highlight the importance of city industry structure in explaining the urban wage premium see Davis and Dingel (2020), Baum-Snow and Pavan (2013), and Kok (2014).

${ }^{4}$ Leading scholars on refugee dispersal programs argue that assimilation is enhanced by placement outside major cities (see, e.g., Damm and Rosholm (2010)). In contrast, we find that placement in a big city causes faster wage gains with experience.
} 
of workers in cities around the world. Furthermore, taken at face value, the similarity of our estimates to Glaeser and Mare (2001) would imply that fixed effect regressions recover estimates not too far from the actual causal return. $^{5}$

Overall, our study confirms that there is a causal urban wage premium and that it arises dynamically, something never previously documented in the literature. Furthermore, we show that this causal benefit works primarily through sorting into different observable types of firms, industries, and occupations across locations. As a result, future research on the wage benefits cities bestow should focus on the determinants of the observable industrial structure of big cities.

\section{BACKGROUND, DATA, AND SAMPLE SELECTION}

In this section, we describe the Danish refugee dispersal policy. We also discuss the sample construction, introduce the map of Danish local labor markets, and show that refugees do not move much after assignment to a location. Our description of the policy draws on Damm and Dustmann (2014), who provide substantially more detail. We also follow their sample construction precisely as outlined in their published work.

\subsection{The Danish Refugee Dispersal Policy}

Before 1986, refugees arriving in Denmark chose their municipalities of residence freely. As a result, a few municipalities played host to a majority of refugees. To ensure all localities shared in integrating refugees, the Danish government, through the Danish Refugee Council, initiated a refugee dis-

\footnotetext{
${ }^{5}$ This could be read to imply that selection into migration is limited.
} 
persal policy in 1986. The program's explicit goal was to distribute refugees across municipalities in proportion to the local population. ${ }^{6}$ Between 1986 and 1998, 76,673 immigrants were granted refugee status (Statistics Denmark 1992, 1997, 2000) and assigned to municipalities. ${ }^{7}$

Under the policy, arriving refugees lived in Red Cross reception centers located across Denmark until receiving asylum. With asylum granted, refugees faced no further legal impediments to labor market participation. Within ten days of the asylum decision, refugees were assigned temporary housing in Denmark's 15 counties. $^{8}$ Each county assigned the refugees to a municipality within the county and helped them find permanent housing. When assigning refugees to a municipality, the council's local office had access only to the birth date, marital status, number of children, and nationality. ${ }^{9}$ Conditional on this information, the assignment was random. Importantly, the council did not have information on years of schooling or family income and did not meet refugees.

Reassignment requests were only allowed after refugees had first moved to the initially assigned municipality. Importantly, our research design relies only on the randomness of the initial assignment. Once settled in the

\footnotetext{
${ }^{6}$ We also thank Bente Bondebjerg from Dansk Flygtningehjælp, who helped run the dispersal program and provided further details on its execution in a phone conversation.

${ }^{7}$ Other notable papers in the exogenous placement literature are Aslund et al. (2009), Shoag and Carollo (2020), Peters (2019), Chetty et al. (2016), Beaman (2011), Edin et al. (2003), Gould et al. (2004), and Imberman et al. (2012). Important papers that use quasiexperimental variation to learn about the strength and nature of agglomeration benefits more generally are Greenstone et al. (2010), Redding and Sturm (2008), Ahlfeldt et al. (2015), Patrick (2016), and Heblich et al. (2018).

${ }^{8}$ (Damm and Dustmann, 2014) perform extensive balancing tests of individual characteristics, such as education, across municipalities. They conclude: "Based on these tests, and the way the policy was implemented, we believe that the allocation of refugees to municipalities was quasi-random, conditional on the characteristics known to the council at assignment." Since their assignment regions are sub-units of the two geographic units (Copenhagen versus Non-Copenhagen) we consider below, this implies random assignment across our units of analysis, conditional on the characteristics known to the council at assignment.

${ }^{9}$ The council tended to assign families with a large number of children to less populated municipalities with higher availability of family homes.
} 


\section{FIGURE 1: COMMUTING ZONES IN DENMARK}

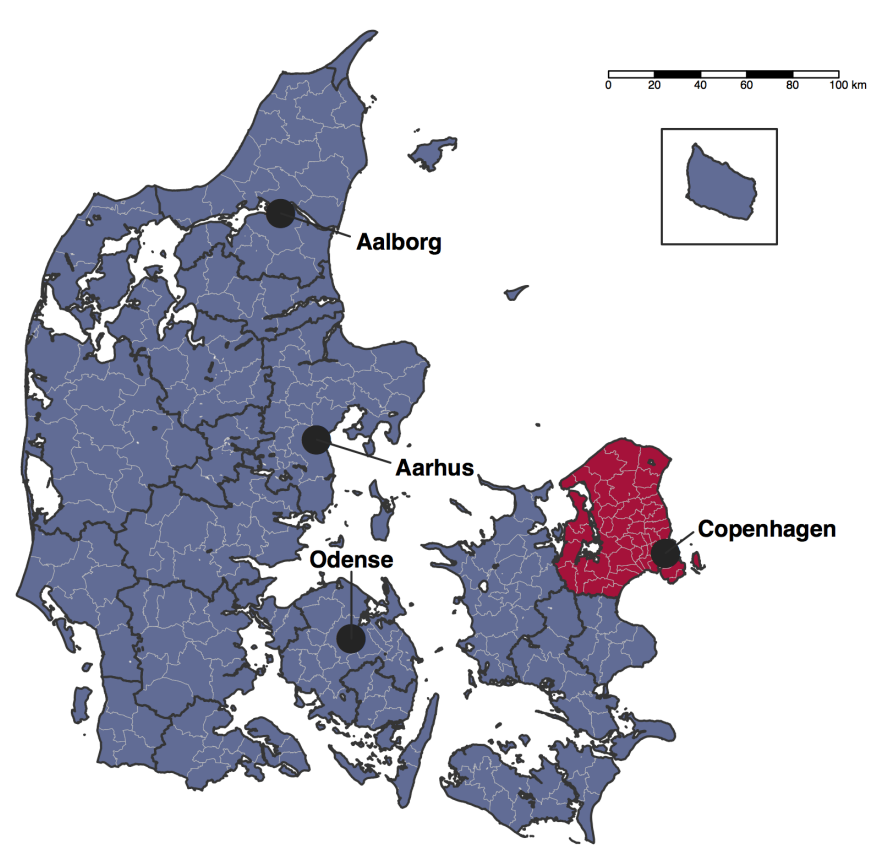

Notes: This figure shows 23 commuting zones (black lines) constructed by the authors using commuting flows of all Danish workers between the 271 municipalities in Denmark in 1986 (light grey lines) following the methodology outlined in Tolbert and Sizer (1996). The Copenhagen assignment area appears in red; the non-Copenhagen assignment area in blue. The box in the top-right corner contains the Bornholm commuting zone, an island off Denmark's eastern shore.

assigned municipality, refugees received social assistance and Danish language courses for 18 months. Although the council urged refugees to stay in the assigned municipality during the entire introductory period, there were no relocation restrictions.

Our empirical strategy exploits the initial quasi-random assignment in two steps. First, we document the treatment effect of initial assignment to a big city on lifetime wage growth. Second, we use the initial assignment's persistence to explore the extent to which we can interpret our results as the causal return to big city experience. 


\subsection{Data Description and Sample Selection}

Our analysis uses administrative data provided by Statistics Denmark. Our core data set is a matched employer-employee panel covering the entire Danish population from 1986 to 2012, including all refugees from the time of being granted asylum. The data set includes detailed labor market information for each individual and year: average hourly wages, total labor earnings, 4-digit occupation codes, and the current municipality of residence and work. ${ }^{10}$ For employing establishments, it contains industry identifiers, employment counts, and total payroll. We enrich the matched data set with other administrative data records on gender, age, years of education, family information on spouses, and the number and age of children in a household. For refugees, the data additionally contain the country of origin and the year of arrival. The Online Appendix provides details on the data and variables used.

Following previous papers exploiting the same natural experiment (Damm and Dustmann, 2014), we restrict our sample to men between the ages of 19 and 55, arriving from Lebanon, Iran, Iraq, Somalia, Sri Lanka, Vietnam, Afghanistan, and Ethiopia between 1986 and 1998. Since family reunified immigrants were not subject to the dispersal policy unless they immigrated shortly after their spouse, we exclude spouses of refugees who immigrated to Denmark more than 12 months later.

Table 1 shows characteristics for both refugees and natives. On average, refugees are younger than Danes, have fewer children, and are less likely to be married. For refugees, the source of education information is a survey conducted upon arrival; for $19 \%$ of refugees in our sample, education infor-

\footnotetext{
${ }^{10}$ Annual hours worked are estimated using information on mandatory pension contributions. This is then used to construct a measure of hourly wages, potentially introducing a source of measurement error. Lund and Vejlin (2015) improve upon Statistics Denmark's estimated annual hours measure for the years 1980-2007, primarily by using additional information on time spent in sickness and leave. All results in this paper are robust to using this improved hourly wage measure.
} 
mation is missing. In the Appendix, we confirm that years of schooling do not differ in an economically meaningful way across initial assignment regions after controlling for the information available to the council. We also compare other outcomes across assignment regions, e.g., employment rates by years in Denmark, of which we offer further discussion below.

Our final sample includes 20,493 male refugees subject to the policy.

\subsection{Local Labor Markets in Denmark}

At the end of our sample period, in 2012, Denmark had a total of 5.6 million inhabitants. Its capital city, Copenhagen, housed 2 million of them in its broader metropolitan area. The remaining 3.6 million people live in three second-tier cities (Aarhus, Aalborg, and Odense), smaller towns, and rural areas. The second-tier cities are an order of magnitude smaller than Copenhagen; Aarhus, the largest, contains around 250,000 people.

We use commuting flows of all Danish workers between Denmark's 271 municipalities in 1986 and a hierarchical clustering algorithm to construct 23 Danish commuting zones. ${ }^{11}$ Figure 1 shows the resulting local labor markets.

Our analysis divides the economy into two locations: the Copenhagen commuting zone and everywhere else. We refer to the Copenhagen commuting zone as Copenhagen or big city, and the remaining commuting zones as non-Copenhagen or elsewhere. ${ }^{12}$

As described above, the policy assigned refugees to municipalities. Quasirandom across these smaller units (as shown in Damm and Dustmann (2014)),

\footnotetext{
${ }^{11}$ Many papers in the economics literature use the commuting zones for the U.S. labor market constructed by Tolbert and Sizer (1996) (e.g., Autor and Dorn (2013)). We use the Tolbert and Sizer (1996) method to construct commuting zones for Denmark.

${ }^{12}$ In the Online Appendix, we show the commuting zones that result from using commuting flows in 1980 and 2000. All results in the paper are robust to the choice of commuting zone delineation.
} 


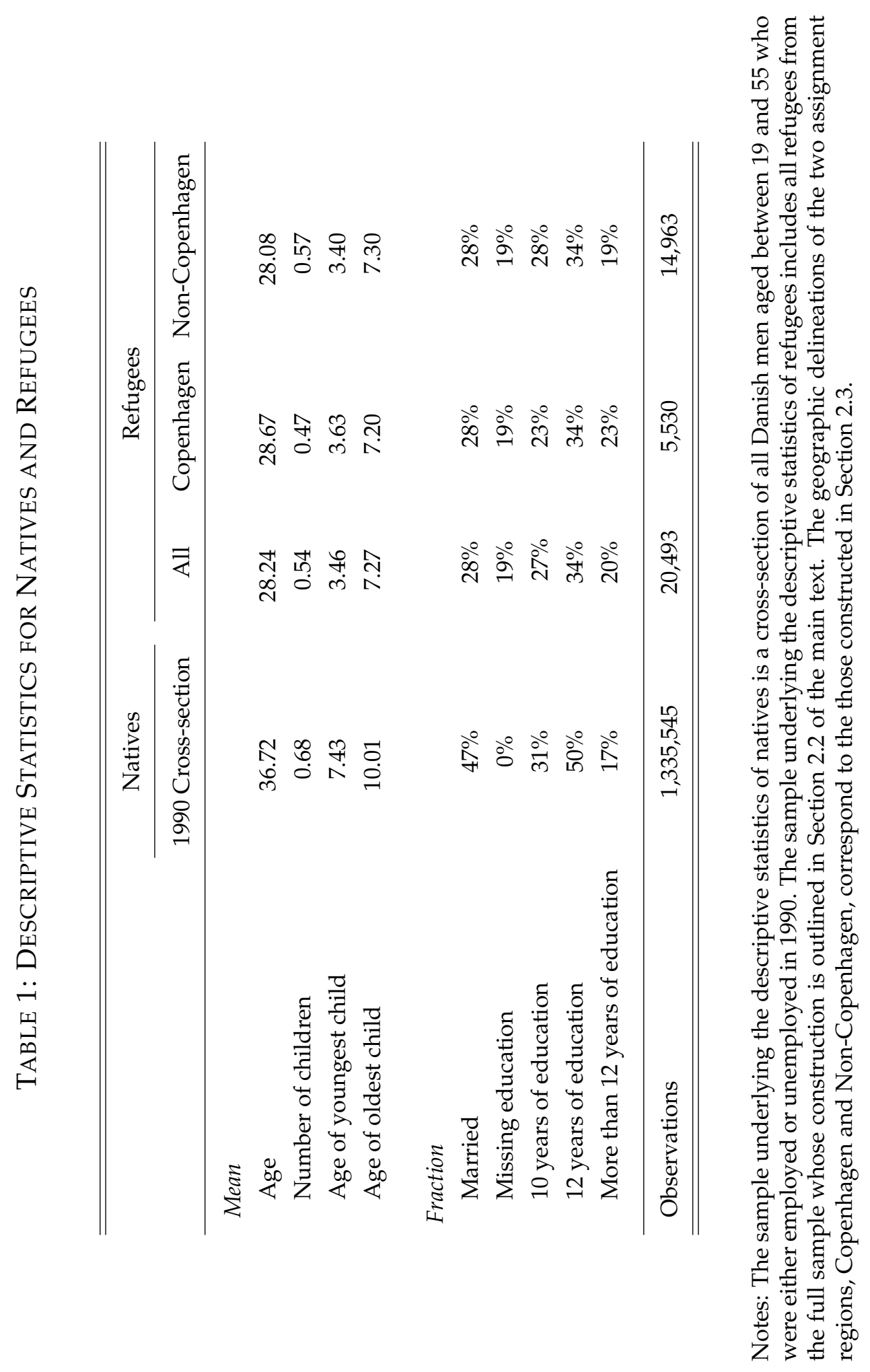


Figure 2: PERSISTENCE OF THE INITIAL

ASSIGNMENT

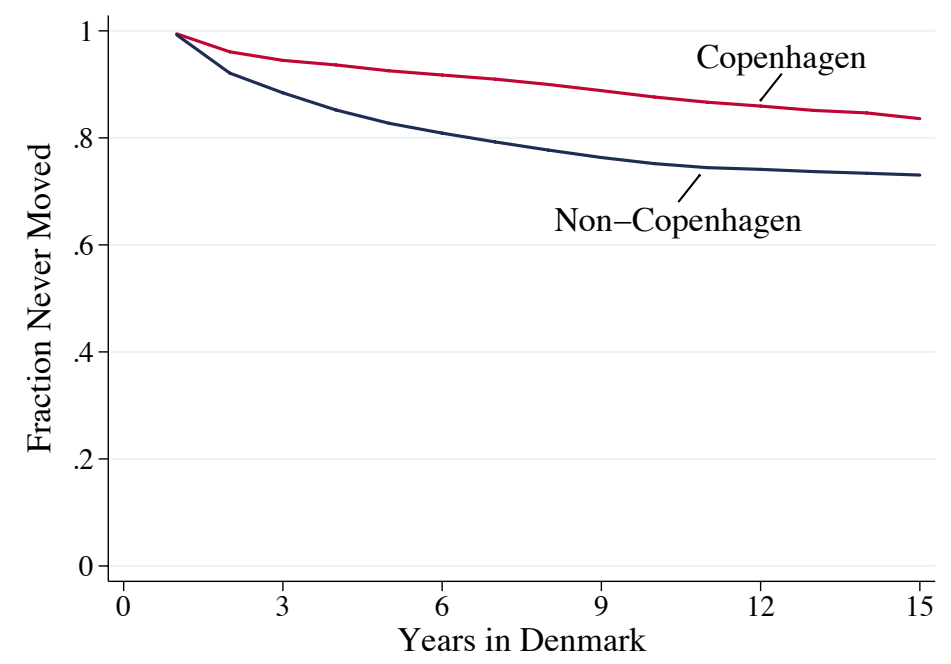

Notes: The sample underlying this figure includes men between the ages of 19 and 55 who arrived from Lebanon, Iran, Iraq, Somalia, Sri Lanka, Vietnam, Afghanistan, and Ethiopia between 1986 and 1998. The figure shows the fraction of refugees who have never changed assignment region (Copenhagen and non-Copenhagen) out of all refugees assigned to a given region, for various years since arrival in Denmark. "Years in Denmark" are the number of years since being granted asylum. The definition of the two assignment regions, Copenhagen and non-Copenhagen, corresponds to the regions constructed in Section 2.3.

implies quasi-random assignment at the level of our two regions of analysis which nest municipalities. We conduct a balancing test for education across our two assignment regions in the Appendix.

\subsection{Persistence of Initial Assignment}

Refugees are free to move after the initial assignment to a region. However, to understand the causal effect of working in Copenhagen on refugees' wages, persistence in the initial assignment is essential. In Figure 2, we show the fraction of refugees who have never moved from their assigned commuting zone by years since arrival in Denmark. Even 15 years after the assignment, $78 \%$ have never left their assigned regions. We discuss the im- 
plications of this persistence for interpreting the treatment effects in Section 3.2. ${ }^{13}$

\section{The Return to Big City EXPerience}

In this section, we divide our sample by initial assignment region and compare the wage-experience and labor supply of the two groups following the assignment. We also discuss the interpretation of the "Copenhagen treatment effect" on wages as the return to big city experience.

\subsection{The Treatment Effect of the Initial Assignment}

In a simple log-linear setting, wage-experience profiles can differ in two ways as a function of initial assignment: intercept and slope. Refugees in one area could earn uniformly higher wages, or see their wages grow faster with experience. We refer to differences in intercept as the static treatment effect and differences in slopes as the dynamic treatment effect. These effects condition only on the initially assigned and not the current location of a refugee. As a result, they are specific to our context and conceptually distinct from the static and dynamic effects of cities in the literature (e.g., Glaeser and Mare (2001)). We explore their interpretation as the return to big city experience in the next subsection.

The only assumption needed to recover the treatment effect of assignment on wages and earnings is random initial assignment conditional on assignment controls. We explore the channels underlying the treatment effects, including effects on the extensive margin of labor supply, in a second step, below.

\footnotetext{
${ }^{13}$ In the Online Appendix, we show the fraction of stayers among refugees of different education levels. Refugees are less likely to leave Copenhagen, regardless of education level. However, refugees with at least a high school diploma are more likely to move to Copenhagen than those with less education.
} 
To document the treatment effects, we estimate the following equation:

$$
w_{i t}=\beta_{1} E_{i t}+\beta_{2} C p h_{i}+\beta_{3}\left(C p h_{i} \times E_{i t}\right)+\phi^{\prime} \boldsymbol{X}_{i t}+\epsilon_{i t} .
$$

$w_{i t}$ is either the log hourly wage or log yearly earnings in Danish Kroner, deflated by an index of Danish nominal wage growth. ${ }^{14} E_{i t}$ is the number of years in which worker $i$ has undertaken paid employment in Denmark prior to year t. $C p h_{i}$ is an indicator variable that takes a value of 1 if the refugee is initially assigned to Copenhagen and 0 otherwise. $\mathbf{X}_{i t}$ is a vector of controls that include cohort fixed effects, nationality fixed effects, and the variables relevant to the assignment of refugees (henceforth "assignment controls").

We report the results for hourly wages in column 1 of Table 2 . There is no significant difference in initial wages across assignment regions. However, each additional year of experience earns refugees assigned to Copenhagen an additional 0.81 percentage point wage increase over and above the return to experience of refugees assigned elsewhere.

In column 2, we report the results for refugees who had at least a high school diploma upon arrival in Denmark (the "High Education" sample henceforth). In column 3, we do the same for refugees with less than a high school diploma, or missing education information (the "Low Education" sample henceforth). The differential slope for wages is very similar across subgroups, and there are no significant differences in initial wages across assignment regions for any of them. Importantly, our findings are not the result of differential aggregate wage trends across assignment regions. In Figure A.1, we show average hourly wages earned by all working Danes, from 1986 to 2010 in Copenhagen and elsewhere. Wage levels between the

\footnotetext{
${ }^{14}$ To construct an index of nominal wage growth, we use the entire population of native workers and apply our sample selection criteria from Section 2.2. We compute average hourly wages in each year relative to 1986 . We use this index to deflate mean hourly wages and earnings for refugees. The results are quantitatively very similar when controlling for aggregate trends using year fixed effects.
} 
two regions did not diverge systematically over our period of study. ${ }^{15}$

In the right-hand panel of Table 2, we repeat these regressions with log earnings as the dependent variable. Earnings are initially lower in the city for both of our sub-populations. However, the estimated coefficient on experience implies that big city earnings catch up after about 3.5 years, and then overtake. Appendix 5 helps reconcile our findings on hourly wages and earnings. There we show that yearly hours worked are initially lower in Copenhagen but increase faster with experience. ${ }^{16}$

Wages and earnings are only observable for individuals who work. Differential selection into work across assignment regions could be a driver of the dynamic treatment effect on wages and earnings.

Table 3 shows the treatment effect on the extensive margin of labor force participation. As our measure of participation, we construct a dummy that takes the value 1 if a worker ever worked and 0 otherwise. We then regress this dummy on an indicator for assignment to Copenhagen, and the assignment controls from specification (1). We run the regression separately for those with high education in Column 1, and those with low education in Column 2. The effect of assignment to a city on labor force participation differs markedly across education groups. For those with high education, assignment to Copenhagen did not significantly affect participation; for those without, it raised the chance of never working by almost $4 \%{ }^{17}$

\footnotetext{
${ }^{15}$ These aggregate wage trends across regions are consistent with differential returns to experience in Copenhagen. Simple models of life-cycle earnings with overlapping generations can exhibit differential wage-experience slopes for individuals across locations and a stable aggregate urban wage premium as new cohorts replace old ones.

${ }^{16}$ In the abstract and the introduction, we state that the wages of refugees placed in Copenhagen grew about 35\% faster with each year of experience relative to their peers assigned elsewhere. To obtain this number, we divide the coefficient on the interaction of experience and initial assignment to Copenhagen by the coefficient on years of experience in Table 2.

${ }^{17}$ Table A.3 in the Appendix shows the treatment effect on labor supply conditional on working at least one year in our sample ("the extensive margin of labor supply"). For this group, we regress an indicator for current employment on a full set of dummies for years spent in Denmark and the assignment controls. For all workers, in both assignment
} 


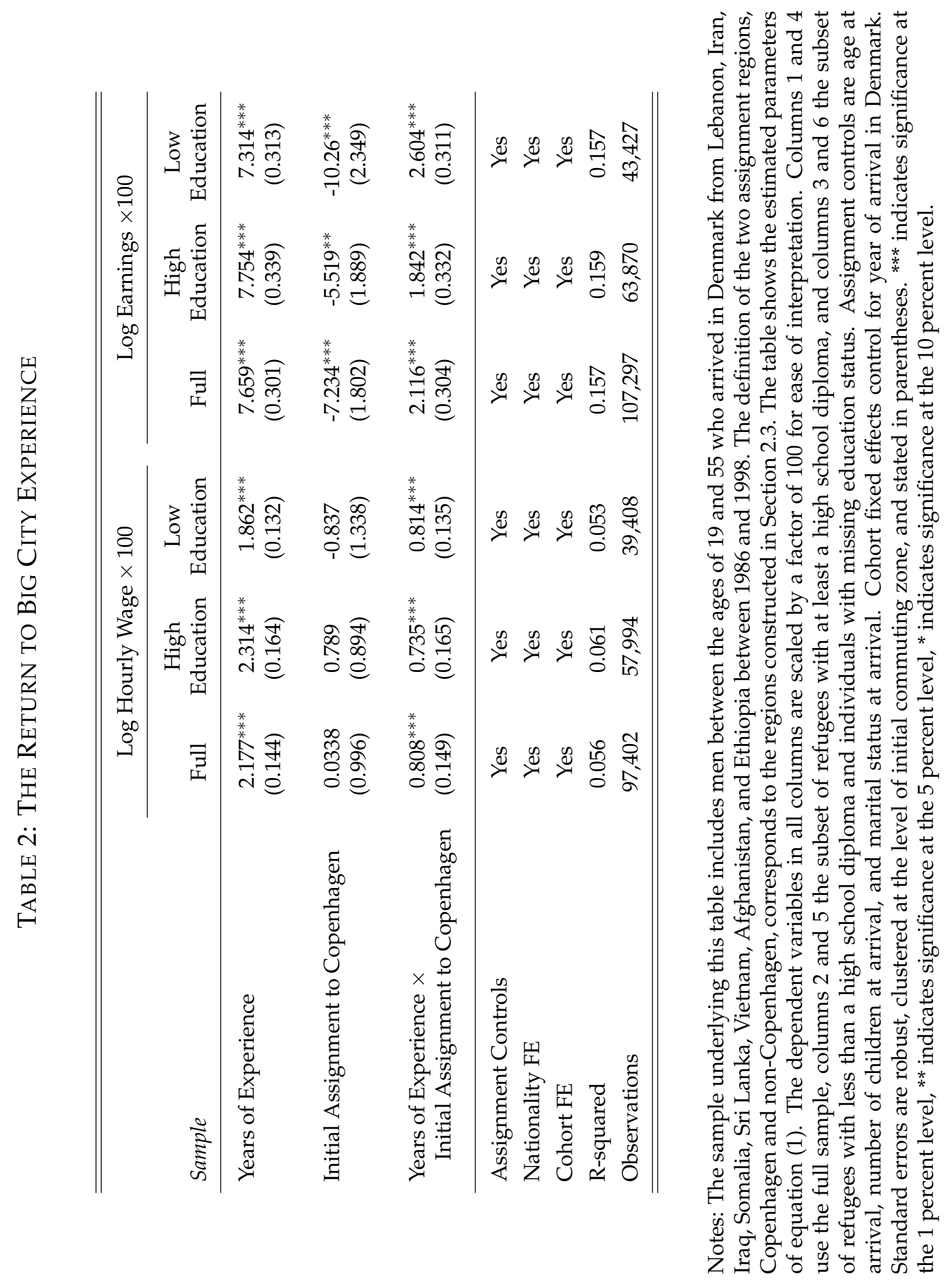


TABle 3: LABOR ForCE PARTICIPATION

\begin{tabular}{lcc}
\hline \hline & \multicolumn{2}{c}{ Indicator for Never Employed } \\
\cline { 2 - 3 } Sample & $\begin{array}{c}\text { High } \\
\text { Education }\end{array}$ & $\begin{array}{c}\text { Low } \\
\text { Education }\end{array}$ \\
\hline \hline Initial Assignment to Copenhagen & 0.00200 & $0.0367^{* * *}$ \\
& $(0.00810)$ & $(0.00886)$ \\
\hline Assignment Controls & Yes & Yes \\
Nationality FE & Yes & Yes \\
Cohort FE & Yes & Yes \\
R-squared & 0.145 & 0.177 \\
Observations & 11,129 & 9,432 \\
\hline \hline
\end{tabular}

Notes: The sample underlying this table includes men between the ages of 19 and 55 who arrived in Denmark from Lebanon, Iran, Iraq, Somalia, Sri Lanka, Vietnam, Afghanistan, and Ethiopia between 1986 and 1998. The definition of the two assignment regions, Copenhagen and non-Copenhagen, corresponds to the regions constructed in Section 2.3. The dependent variable is an indicator taking a value of 1 if the individual never took up paid employment between 1986-2012. Column 1 uses the subsample of all refugees with at least a high school diploma and Column 2 the subsample with less than a high school diploma and those with missing information on years of education. Robust standard errors clustered at the level of the initial commuting zone. Standard errors in parentheses. ${ }^{* * *}$ indicates significance at the 1 percent level, ${ }^{* *}$ indicates significance at the 5 percent level, * indicates significance at the 10 percent level.

The treatment induced selection into the labor force in the Low Education sample could reflect that those with little formal education find it particularly challenging to join the labor force in the city compared to elsewhere and that those who do join are more able than those who do not. For the remainder of the paper, we focus on those with high education, who comprise $55 \%$ of our baseline sample. For these workers, we can rule out selection into the labor force as a driver of the dynamic treatment effect.

In the Online Appendix, we consider a range of robustness exercises on our

groups, employment rates rise steadily throughout our sample period. 
wage and earnings regressions. First, we show that the results are unaffected by using different definitions of the underlying commuting zones. ${ }^{18}$ Second, we demonstrate that assignment to a second-tier city (Aalborg, Aarhus, or Odense), results in a weaker dynamic treatment effect. Similarly, when we drop refugees assigned to second-tier cities from the sample and compare workers assigned to Copenhagen to those assigned to even smaller cities, we find an even more substantial dynamic treatment effect. These results suggest that the return to big city experience is monotonic in city size. Third, we repeat our baseline regression non-parametrically. We continue to find no static effect for wages, and a negative static effect for earnings that is not significant. ${ }^{19}$ Fourth, we consider an alternative specification where years of experience interact with the assignment region's population size and find the return to experience to be increasing in population size. Fifth, we replace years of experience with years of potential experience (i.e., years since arrival in Denmark), and find a quantitatively smaller dynamic effect, reflecting that refugees take time to transition into the labor force.

\subsection{Treatment Effects and the Return to Big City Experience}

In the previous section, we showed that the average wage-experience profile among refugees initially assigned to Copenhagen is steeper than that of those assigned elsewhere. However, the fact that workers migrate after assignment complicates the interpretation of the dynamic treatment effect as the statistical return to experience earned in Copenhagen. In this section, we discuss the relationship between our measured dynamic treatment effect and the true return to big city experience, given worker relocation after as-

\footnotetext{
${ }^{18}$ Using the Eurostat definition of the Copenhagen commuting zone also leaves our results unchanged.

${ }^{19}$ In line with a large literature (see, e.g., Lagakos et al. (2018)), we find concavity in the returns to experience. However, the treatment effect itself is broadly linear in years of experience, and the linear model captures the size of the effect after 15 years well.
} 
signment.

Suppose there are two city types indexed by $c$, big cities $(c=b)$ and small cities $(c=s)$, and that after demeaning all variables, the log hourly wage of worker $i$ in city $c$ at time $t$ is given by the following equation:

$$
w_{i t}^{c}=\gamma^{s} \times E_{i t}^{s}+\left(\gamma^{b}+\theta_{i}\right) \times E_{i t}^{b}+\eta_{i t}^{c}
$$

where $\theta_{i}$ is a scalar indexing person $i^{\prime}$ s unobserved ability, $E_{i t}^{c}$ are years of experience accumulated in cities of type $c$, and $\gamma^{c}$ is the causal return to this type of experience. $\eta_{i t}^{c}$ is a structural residual that captures other determinants of wages (e.g., good firm matches and occupation shifters). $\mathbb{E}\left[E_{i t}^{s} \eta_{i t}\right]$ and $\mathbb{E}\left[E_{i t}^{b} \eta_{i t}\right]$ are not necessarily zero.

We assume $\gamma^{b} \geq \gamma^{s}$. As a result, equation (2) allows for a wage growth premium from working in a big city. Equation (2) reflects that workers with higher unobserved ability may find big city experience more valuable. This potential complementarity introduces the selection problem central to this paper. ${ }^{20}$ If more able workers benefit more from being in a city and hence move there at higher rates, higher wages in cities conditional on observables could reflect the resulting difference in average ability across locations rather than a productive advantage of the city itself. In particular, we define the causal return to big city experience, denoted by $\gamma$, as the extra return to an additional year of experience collected in a big relative to a small city, such that $\gamma \equiv \gamma^{b}-\gamma^{s}$.

We partition the set of refugees into two subsets: $\mathcal{B}$ is the set of workers assigned to a big city, $\mathcal{S}$ that of those assigned to a smaller city. The natural experiment's value is to ensure that average latent ability is the same across these groups, such that $\mathbb{E}\left[\theta_{i} \mid i \in \mathcal{B}\right]=\mathbb{E}\left[\theta_{i} \mid i \in \mathcal{S}\right]$ holds. $^{21}$

\footnotetext{
${ }^{20}$ The wage process in equation (2) is similar to other specifications in the urban economics literature (see, e.g., Baum-Snow and Pavan (2012) and De La Roca and Puga (2017)).

${ }^{21}$ Equation (2) provides a simple framework to think about the interpretation of the dynamic treatment effect. In particular, the role of unobserved heterogeneity is reduced to an
} 
The migration of workers across assignment regions complicates the mapping between the estimated treatment effect and the wage process parameters. As a benchmark, consider an "ideal" setting without migration, assuming that

(A.1.) Workers never move across assignment regions.

Assumption A.1. guarantees that refugees accumulate all experience in the assignment region. As a result, treatment effects - which condition on initial assignment only - recover the statistical return to big city experience. To see this, consider regressing wages on experience for workers in groups $\mathcal{S}$ and $\mathcal{B}$ separately. The difference in the OLS estimates of the experience coefficients, $\hat{\gamma}^{\mathcal{B}}-\hat{\gamma}^{S}$, obeys

$$
\operatorname{plim} \hat{\gamma}^{\mathcal{B}}-\hat{\gamma}^{\mathcal{S}}=\underbrace{\gamma^{b}+\left(\sigma_{E}^{b}\right)^{-2} \mathbb{E}\left[E_{i t}^{b} \eta_{i t}\right]}_{\equiv \beta^{b}}-\underbrace{\left(\gamma^{S}+\left(\sigma_{E}^{S}\right)^{-2} \mathbb{E}\left[E_{i t}^{S} \eta_{i t}\right]\right)}_{\equiv \beta^{S}} \equiv \beta,
$$

where $\sigma_{E}^{c}$ is the variance of $E_{i t}^{c}{ }^{22}$ We define $\beta$ as the return to an extra year of experience collected in the big relative to the small city. $\beta$ is the main object of interest of the paper, and we refer to it as the return to big city experience. It consists of both the causal return to big city experience, $\gamma=\gamma^{b}-\gamma^{s}$, and terms reflecting other determinants of wages that covary with experience. For example, an extensive literature suggests that as workers gain experience, they work for increasingly more productive firms, i.e., climb a job ladder (see, e.g. Baum-Snow and Pavan (2012)). If workers climb such ladders faster in big cities, this would contribute to the return to big city experience, $\beta$, through the $\mathbb{E}\left[E_{i t}^{c} \eta_{i t}\right]$ term. $^{23}$

effect of unobserved ability on wages. Other forms of unobserved heterogeneity, including sorting on preferences for amenities, comparative advantage, and multi-dimensional types (as in Lindenlaub (2017)), are likely to be important in practice.

${ }^{22}$ This holds under the assumption that unobserved ability does not affect the probability of employment, i.e., $\mathbb{E}\left[E_{i t}^{s} \mid \theta_{i}\right]=\mathbb{E}\left[E_{i t}^{s}\right]$, and similarly for big cities $b$.

${ }^{23}$ This highlights that even in the "ideal" setting (under Assumption A.1.) we cannot isolate the causal return to big city experience, $\gamma$. To isolate $\gamma$ in a natural experiment, workers would have to be randomly assigned both across space and also across firms within 
The estimated dynamic treatment effect above recovers $\beta$ under Assumption A.1. However, Figure 2 shows that Assumption A.1. is too stark; most, but not all, workers stay in their assigned region. Migration changes the interpretation of the estimated dynamic treatment effect. To understand how, we replace A.1. with a stylized assumption about the process of relocation. For illustration, we assume that

(A.2) A faction $\varkappa$ of workers moves immediately across assignment regions and then does not move again.

Figure 2 motivates these assumptions as a stylized description of the data: some workers move quickly after assignment. ${ }^{24}$ Denote the set of individuals in group $\mathcal{S}$ who relocate from $s$ to $b$ by $\mathcal{M}_{\mathcal{S}}$, with $\mathcal{M}_{\mathcal{B}}$ defined analogously. Again running separate regressions on the two assignment groups and differencing the coefficients on experience yields:

$$
\operatorname{plim} \hat{\gamma}^{\mathcal{B}}-\hat{\gamma}^{S}=\beta-\underbrace{2 \varkappa \beta}_{\text {Migration Bias }}-(\underbrace{\varkappa \mathbb{E}\left[\theta_{i} \mid i \in \mathcal{M}_{\mathcal{S}}\right]-(1-\varkappa) \mathbb{E}\left[\theta_{i} \mid i \in \mathcal{M}_{\mathcal{B}}\right]}_{\text {Selection Bias }}) .
$$

This equation shows the two sources of bias relocation introduces. These biases drive a wedge between the measured dynamic treatment effect and the true return to big city experience, $\beta$.

Migration bias occurs as long as any worker migrates upon assignment, i.e., $\varkappa>0$ holds. In this case, the dynamic treatment effect underestimates the return to big city experience, $\beta$. Movers from $S$ would see faster wage growth after moving to the big city, but be counted into the $S$ stratification, and vice versa. As a result, the estimated wage-experience profile difference between the two assignment groups would shrink, and the measured dynamic treatment effect would underestimate the return to big city experience, $\beta$.

locations over their working lifetimes.

${ }^{24}$ Further assumptions about moving over time, or different fractions moving, can easily be incorporated, without adding additional insight to the idea presented here. 
Second, selection bias arises if $\mathbb{E}\left[\theta_{i} \mid i \in \mathcal{M}_{\mathcal{S}}\right]$ or $\mathbb{E}\left[\theta_{i} \mid i \in \mathcal{M}_{\mathcal{B}}\right]$ are non-zero, i.e., movers differ from non-movers in unobserved ability. ${ }^{25}$ Suppose, as is common in the literature, more able workers are more likely to move to the city, and less able workers to leave the city, so that $\mathbb{E}\left[\theta_{i} \mid i \in \mathcal{M}_{\mathcal{S}}\right]>0>$ $\mathbb{E}\left[\theta_{i} \mid i \in \mathcal{M}_{\mathcal{B}}\right]{ }^{26}$ The high-ability movers will nevertheless be counted in group $\mathcal{S}$, shrinking the gap in estimated slopes between the two treatment groups. As a result, the dynamic treatment effect further underestimates the return to big city experience. ${ }^{27}$

The above analysis suggests that under the assumption that $\mathbb{E}\left[\theta_{i} \mid i \in \mathcal{M}_{\mathcal{S}}\right]>$ $0>\mathbb{E}\left[\theta_{i} \mid i \in \mathcal{M}_{\mathcal{B}}\right]$, we can construct an informative upper bound on the return to big city experience, $\beta$. To do so we re-estimate our baseline equation (1) only on individuals who never move across assignment regions. First, since these workers do not move, these estimates do not suffer from the first source of downward bias we identified above. Second, we remove on average high-ability individuals whose wages grow faster with experience after moving to Copenhagen. This leaves on average lower ability individuals in our non-Copenhagen stratification than compared to the randomly selected sample. Likewise, the Copenhagen group earns all its experience in Copenhagen and contains those least likely to leave Copenhagen, since it benefits them most. Jointly, this has the effect of biasing upwards our estimate of the return to big city experience, $\beta .^{28}$

Table 4 shows the results of re-estimating the treatment regression in (1) on the stayer population. The results support our simple selection story: the

\footnotetext{
${ }^{25}$ There is ample empirical evidence for the importance of selection in individual migration decisions, e.g., Borjas (1987), McKenzie et al. (2010), Young (2013), Lagakos and Waugh (2013), Behrens et al. (2014) and Eeckhout et al. (2014).

${ }^{26}$ In the Online Appendix, we show that more educated workers are more likely to move to Copenhagen than less educated ones. To the extent that educational attainment covaries with unobserved ability, this serves as empirical support for this stylized assumption.

${ }^{27}$ In the presence of selection on unobserved multi-dimensional types as in Lindenlaub (2017) much stronger assumptions are required to interpret our estimates.

${ }^{28}$ In reality, moving fractions differ across regions as Figure 2 shows. However, indexing $\varkappa$ by location does not affect this bound.
} 


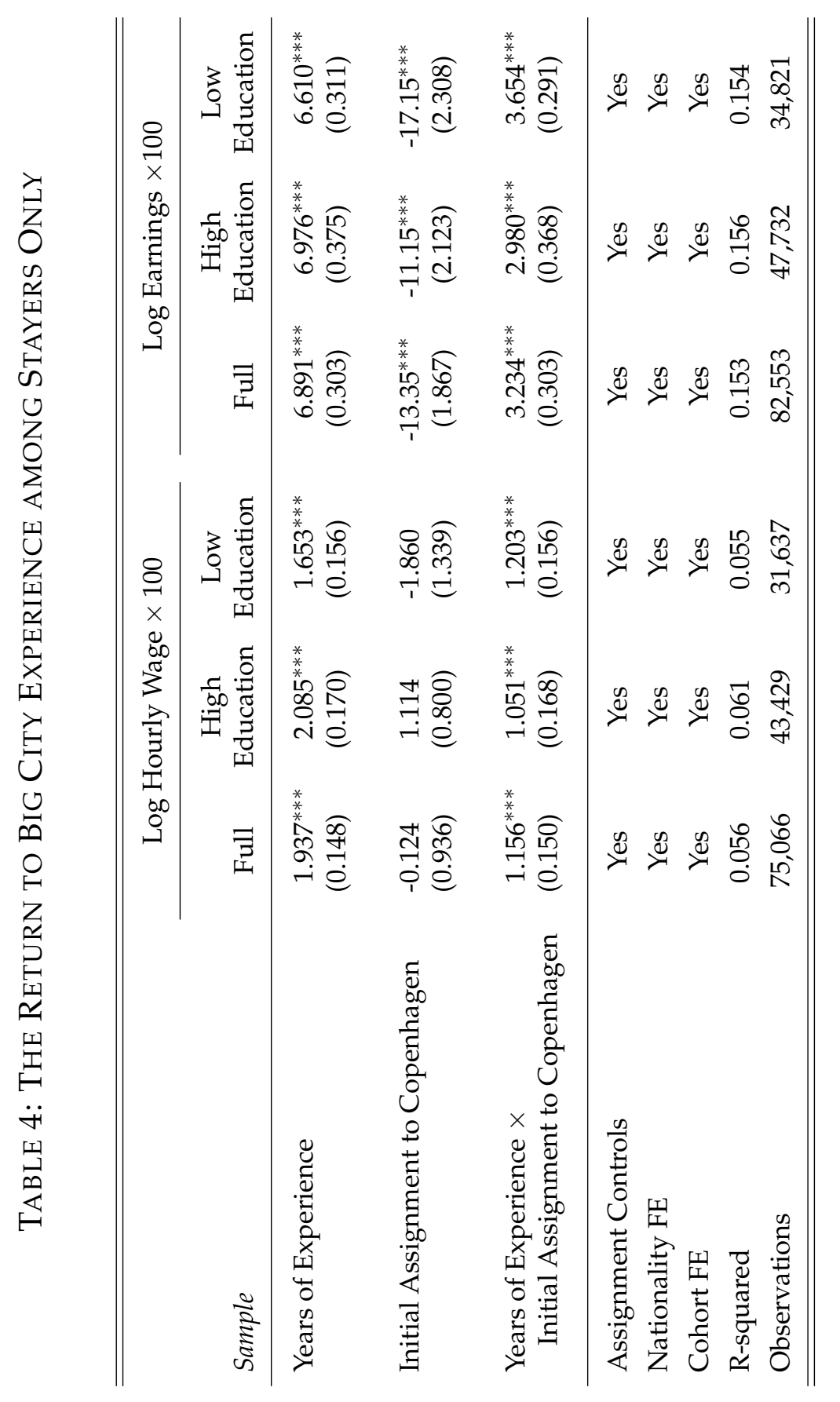

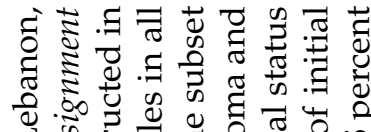

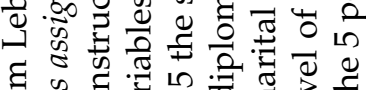

要

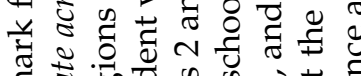

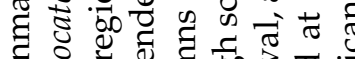

จำ

马 ङ

ช。워

论

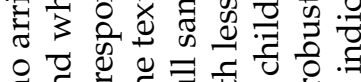

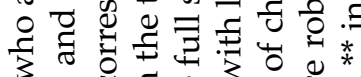

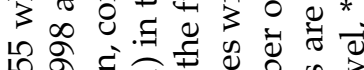

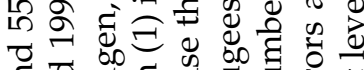

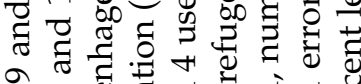

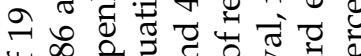

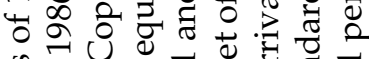

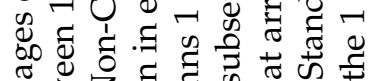

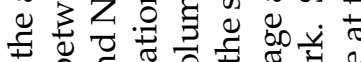

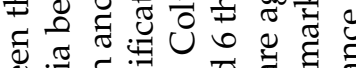

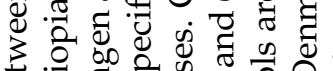

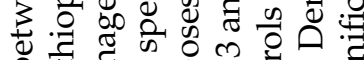

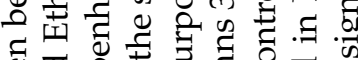

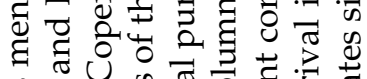

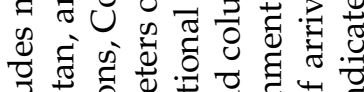

可.

.

응

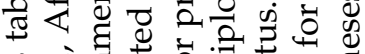

हो दे चै :

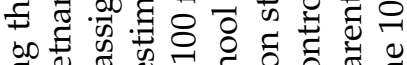

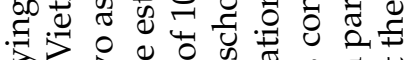

年

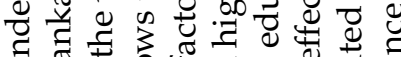

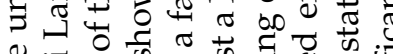

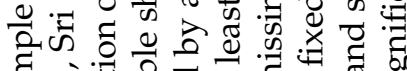
द्व

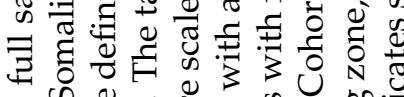
क 0 \%

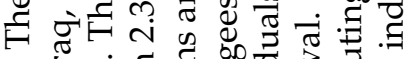

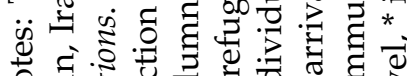

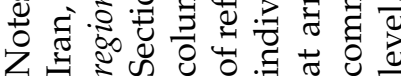


differential value of experience accumulated in Copenhagen is uniformly higher in the sample of stayers than in the full sample (see Table 2 above). Comparing the results in Tables 4 and 2 suggests that the return to big city experience lies in the range of $0.74 \%-1.05 \%$ for the High Education sample, a relatively tight bound. For the rest of the paper, we refer to the dynamic treatment effect and the return to big city experience interchangeably.

\section{Observable Determinants OF THE RETURN TO BIG City EXPERIENCE}

In this section, we use the wealth of information on workers in the Danish administrative data to understand the observable determinants of the return to big city experience.

First, we investigate whether observable differences in refugees' jobs across assignment regions can explain the return to big city experience. For example, our estimated dynamic treatment effect could reflect that refugees started in similar entry-level jobs across labor markets, but sorted into more high-paying jobs in Copenhagen than elsewhere in later years. Second, we study other observables, including educational uptake and the effects of ethnic enclaves, and find them less important in explaining the return to big city experience.

\subsection{Sorting Across Job Types}

Previous work documented that cities host different industries and occupations than more rural areas (see, e.g., Davis and Dingel (2020) and Duranton and Puga (2005)) and that firms located in bigger cities tend to be more productive (see, e.g., Combes et al. (2012)). We provide evidence that jobs undertaken by our two groups of refugees differ by occupation, industry, 
and firm-type, and increasingly so over time.

We group the 20 industries available in our data into three groups: lowskill services (e.g., accommodation and food services), high-skill services (e.g., professional, scientific, and technical activities), and manual industries (e.g., manufacturing or construction). Similarly, we assign the $10 \mathrm{occu}-$ pations to three groups: high-skill occupations (e.g., managers and professionals), low-skill occupations (e.g., service and sales workers), and manual occupations (e.g., plant and machine operators). ${ }^{29}$ To create establishment types, we compute the average hourly wage among all Danes for each establishment in Denmark. We order establishments by the average hourly wage paid out to their workers and denote the set of establishments that (a) pay the highest hourly wages and (b) account for about $30 \%$ of Denmark-wide employment as high-wage establishments (or firms). We refer to firm types and establishment types interchangeably, since most firms in our sample are single-establishment operations.

Across assignment regions, many refugees initially start their careers doing low-skill service work. However, as they gain experience, refugees assigned outside Copenhagen transition predominantly into manual work, while those placed in Copenhagen move into high-skill work. At 15 years of experience, $40 \%$ of refugees assigned to Copenhagen work in high-skill occupations compared to $27 \%$ of those assigned elsewhere. These sorting patterns across industries reflect those across occupations: as they accumulate experience, refugees assigned to Copenhagen become more likely to work in the high-skill services, while those assigned elsewhere increasingly sort into manual industries such as manufacturing. ${ }^{30}$ We also find that, as they accumulate experience, refugees assigned to Copenhagen are more likely to work at high-wage firms compared to refugees assigned elsewhere. ${ }^{31} \mathrm{We}$

\footnotetext{
${ }^{29}$ The Online Appendix list all industries and occupations and their assigned groups.

${ }^{30}$ The Online Appendix shows the sorting patterns with experience for the full Danish population. Danes do more high-skill and less low-skill service work than refugees.

${ }^{31}$ In line with previous findings in the urban literature, high-wage establishments tend
} 
provide figures illustrating these facts in the Online Appendix.

Overall, as they accumulate experience, refugees assigned to Copenhagen appear to work in different types of jobs compared to those assigned elsewhere: they increasingly sort towards high-wage firms and high-skill occupations in the high-skill service industry. We now test whether refugees' differential job choices can account for the wage growth premium associated with Copenhagen.

We re-estimate equation (1) with fixed effects for establishment types, industries, and occupation. We use the binary firm types introduced above as fixed effects for establishments, but include separate fixed effects for the full set of occupations and industries listed in Appendices A.3 and A.2. Column 1 of Table 5 repeats the baseline treatment regression from Table 2 above for comparison. Column 2 adds establishment type fixed effects, column 3 further includes occupation fixed effects, and column 4 adds industry fixed effects.

Including establishment-type fixed effects reduces our baseline coefficient to $0.588 \%$, suggesting that differential sorting across establishment types is an important component of the return to big city experience. Column 3 shows that including occupation fixed effects further decreases the coefficient on the return to big city experience to $0.409 \%$. This reduction reflects the descriptive patterns above: refugees assigned to Copenhagen have a higher chance of working in high-skill jobs, and this advantage widens over time. For industries, we find that workers in Copenhagen are more likely to work in skill-intensive business services. Outside of the capital, manual jobs in agriculture and manufacturing are more frequent. The fixed effects for 1-digit industries included in column 4 further decrease the return to big city experience to $0.371 \%$. We conclude that, jointly, these observable job characteristics account for a large fraction of the return to big city expeto be large and disproportionately present in Copenhagen (see Combes et al. (2012), Mion and Naticchioni (2009), and Dauth et al. (2018)). 
rience. $^{32}$

In summary, the results in this subsection suggest that the gradual sorting of refugees in Copenhagen into productive jobs is the principal channel behind the dynamic treatment effect identified above. Cities of different sizes differ systematically in occupation, industry, and firm type composition. The fact that these three observable correlates explain most of the return to big city experience premium suggests that the causal return we document is likely not specific to our setting. Our findings are in line with recent work by Dauth et al. (2018)who provide evidence for the better matching of workers in big cities.

\subsection{Education, Ethnic Enclaves, and Hours Worked}

Other observable factors may spur wage growth for refugees in Copenhagen. We investigate three channels that ex-ante appear particularly important in our setting: acquiring more formal education, the effect of ethnic enclaves, and differences in the intensive margin of hourly labor supply.

We first test whether refugees initially assigned to Copenhagen take-up more years of education than those assigned elsewhere. Table A.1 in the Appendix shows the result of a t-test of mean differences in educational take-up between the two assignment groups. Differences in take-up across assignment regions are minimal: about equal to one additional month of education on average. Including years of education in the baseline estimating equation (1) leaves the return to big city experience unchanged. In conclusion, educational take-up differences across commuting zones cannot explain the return to big city experience identified above.

If collocating with other immigrants of their nationality in Copenhagen over time gives refugees access to informal networks and employment oppor-

\footnotetext{
${ }^{32}$ For completeness, in the Online Appendix, we show the estimates of the return to big city experience for all possible combinations of fixed effects.
} 
TABle 5: MeCHANisMS BEHIND THE RETURN TO BIG City EXPERIENCE

\begin{tabular}{lcccc}
\hline \hline & \multicolumn{4}{c}{ Log Hourly Wage $\times 100$} \\
\cline { 2 - 5 } Sample & $\begin{array}{c}\text { High } \\
\text { Education }\end{array}$ & $\begin{array}{c}\text { High } \\
\text { Education }\end{array}$ & $\begin{array}{c}\text { High } \\
\text { Education }\end{array}$ & $\begin{array}{c}\text { High } \\
\text { Education }\end{array}$ \\
\hline Years of Experience & $2.314^{* * *}$ & $1.962^{* * *}$ & $1.784^{* * *}$ & $1.601^{* * *}$ \\
& $(0.164)$ & $(0.156)$ & $(0.127)$ & $(0.117)$ \\
Initial Assignment to Copenhagen & 0.789 & -0.399 & 0.372 & 0.302 \\
& $(0.894)$ & $(0.682)$ & $(0.553)$ & $(0.555)$ \\
Years of Experience $\times$ & & & & \\
$\quad$ Initial Assignment to Copenhagen & $\left(0.735^{* * *}\right.$ & $0.588^{* * *}$ & $0.409^{* *}$ & $0.371^{* *}$ \\
& & $(0.151)$ & $(0.122)$ & $(0.107)$ \\
Assignment Controls & Yes & Yes & Yes & Yes \\
Nationality FE & Yes & Yes & Yes & Yes \\
Cohort FE & Yes & Yes & Yes & Yes \\
High-Wage Establishment FE & No & Yes & Yes & Yes \\
Occupation FE & No & No & Yes & Yes \\
Industry FE & No & No & No & Yes \\
R-Squared & 0.061 & 0.132 & 0.185 & 0.221 \\
Observations & 57,994 & 57,994 & 48,183 & 44,135 \\
\hline \hline
\end{tabular}

Notes: The sample underlying this table includes men between the ages of 19 and 55 with at least a high-school education who arrived in Denmark from Lebanon, Iran, Iraq, Somalia, Sri Lanka, Vietnam, Afghanistan, and Ethiopia between 1986 and 1998. The definition of the two assignment regions, Copenhagen and non-Copenhagen, corresponds to the regions constructed in Section 1 . The table presents the estimated parameters of the specification in equation (1) in the text. The dependent variables in all columns are scaled by a factor of 100 for presentational purposes. Column 1 replicates column 2 from Table 2 above. Columns 2-4 add establishment, occupation, and industry fixed effects to the baseline estimates in column 1. Assignment controls are age at arrival, number of children at arrival, and marital status at arrival. Cohort fixed effects control for year of arrival in Denmark. The industries and occupations controlled for via fixed effects are listed in the Online Appendix. Standard errors are robust, clustered at the level of initial commuting zone, and stated in parentheses. ${ }^{* * *}$ indicates significance at the 1 percent level, ${ }^{* *}$ indicates significance at the 5 percent level, * indicates significance at the 10 percent level. 
tunities not available elsewhere, this could explain some of the measured return to big city experience. ${ }^{33}$ To test this channel, we include the stock of co-nationals in the municipality of assignment in the year of assignment in our baseline specification. ${ }^{34}$ Table A.4 in the Appendix shows that our baseline estimates are unchanged. On average, refugees assigned to ethnic enclaves receive lower wages and earnings without affecting the estimated return to big city experience. As a result, differences in refugee assimilation do not seem to affect our results. ${ }^{35}$

Lastly, Figure A.3 in the Appendix shows that the intensive margin of hours cannot explain the return to big city experience in our High Education sample. Average hours worked do not differ significantly across assignment regions.

\section{CONCLUDING REMARKS}

In this paper, we provide causal evidence for higher returns to experience in big cities using a natural experiment. Gradual sorting into the industries, occupations, and firms typically found in large cities accounts for a large part of this return to big city experience. Our findings suggest that theories of the determinants of the observable industrial structure of big cities are central to understanding the fundamental determinants of wage differences across space.

\footnotetext{
${ }^{33}$ The influential paper by Edin et al. (2003), using a similar refugee placement program, finds that enclaves only affect wage paths for low-skill workers. These findings attenuate concerns about the interference of enclaves with the wages of refugees in our High Education sample.

${ }^{34}$ There is variation in these stocks across the municipalities of assignment within the Copenhagen commuting zone.

${ }^{35}$ In fact, Damm and Rosholm (2010) argue that one motivation for the refugee dispersal policy was that refugees tended to assimilate faster outside large metropolitan areas, which absent other channels would work against our finding of a return to big city experience.
} 


\section{REFERENCES}

Ahlfeldt, G. M. And E. Pietrostefani (2019): “The Economic Effects of Density: A Synthesis," Journal of Urban Economics, 111, 93-107.

Ahlfeldt, G. M., S. J. Redding, D. M. Sturm, AND N. Wolf (2015): "The economics of density: Evidence from the Berlin Wall," Econometrica, $83,2127-2189$.

Allen, T. And C. ARKOlaKis (2014): "Trade and the Topography of the Spatial Economy," The Quarterly Journal of Economics, 129, 1085-1140.

Aslund, O., J. Osth, AND Y. Zenou (2009): “How Important is Access to Jobs? Old Question-Improved Answer," Journal of Economic Geography, $10,389-422$.

Autor, D. AND D. Dorn (2013): "The Growth of Low-skill Service Jobs and the Polarization of the US Labor Market," American Economic Review, 103, 1553-97.

BAUM-SNOW, N. AND F. FERREIRA (2015): “Causal Inference in Urban and Regional Economics," in Handbook of Regional and Urban Economics, Elsevier, vol. 5, 3-68.

Baum-SnOW, N. And R. PAVAn (2012): “Understanding the City Size Wage Gap," The Review of Economic Studies, 79, 88-127.

- (2013): "Inequality and City Size," Review of Economics and Statistics, 95, 1535-1548.

BEAmAN, L. A. (2011): "Social Networks and the Dynamics of Labour Market Outcomes: Evidence from Refugees Resettled in the US," The Review of Economic Studies, 79, 128-161. 
Behrens, K., G. Duranton, And F. Robert-Nicoud (2014): "Productive Cities: Sorting, Selection, and Agglomeration," Journal of Political Economy, 122, 507-553.

BORJAS, G. J. (1987): "Self-Selection and the Earnings of Immigrants," The American Economic Review, 531-553.

Chetty, R., N. Hendren, AND L. F. Katz (2016): “The Effects of Exposure to Better Neighborhoods on Children: New Evidence from the Moving to Opportunity Experiment," The American Economic Review, 106, 855-902.

Combes, P.-P., G. Duranton, And L. Gobillon (2008): “Spatial Wage Disparities: Sorting Matters!" Journal of Urban Economics, 63, 723-742.

Combes, P.-P., G. Duranton, L. Gobillon, D. Puga, and S. Roux (2012): "The Productivity Advantages of Large Cities: Distinguishing Agglomeration From Firm Selection," Econometrica, 80, 2543-2594.

DAMm, A. P. (2009): "Determinants of Recent Immigrants Location Choices: Quasi-experimental Evidence," Journal of Population Economics, $22,145-174$.

Damm, A. P. And C. Dustmann (2014): “Does Growing Up in a High Crime Neighborhood Affect Youth Criminal Behavior?" The American Economic Review, 104, 1806-1832.

Damm, A. P. AND M. Rosholm (2010): “Employment Effects of Spatial Dispersal of Refugees," Review of Economics of the Household, 8, 105-146.

Dauth, W., S. Findeisen, E. Moretti, And J. Suedekum (2018): "Matching in Cities," Tech. rep., National Bureau of Economic Research.

DAVIS, D. R. AND J. I. Dingel (2020): “The Comparative Advantage of Cities," Journal of International Economics, 103291. 
D'Costa, S. And H. G. Overman (2014): “The Urban Wage Growth Premium: Sorting or Learning?" Regional Science and Urban Economics, 48, 168-179.

De la Roca, J., G. I. Ottaviano, And D. Puga (2014): "City of Dreams,"

De La RocA, J. AND D. PugA (2017): “Learning by Working in Big Cities," The Review of Economic Studies, 84, 106-142.

DenMARK, C. S. (Various Years): "Statistical Yearbook (Statistisk Arbog)," Statistics Denmark Publication.

Duranton, G. AND D. Puga (2004): "Micro-foundations of Urban Agglomeration Economies," in Handbook of Regional and Urban Economics, Elsevier, vol. 4, 2063-2117.

- (2005): "From Sectoral to Functional Urban Specialisation," Journal of Urban Economics, 57, 343-370.

Dustmann, C., K. Vasiljeva, And A. P. Damm (2019): “Refugee Migration and Electoral Outcomes," Review of Economic Studies, Forthcoming.

EdIN, P.-A., P. FredriKsSON, AND O. ÅsLund (2003): “Ethnic Enclaves and the Economic Success of Immigrants - Evidence from a Natural Experiment," The Quarterly Journal of Economics, 118, 329-357.

Eeckhout, J., R. Pinheiro, And K. Schmidheiny (2014): “Spatial Sorting," Journal of Political Economy, 122, 554-620.

Glaeser, E. L. AND D. C. MARE (2001): “Cities and Skills," Journal of Labor Economics, 19, 316-342.

Gould, E. D. (2007): “Cities, Workers, and Wages: A Structural Analysis of the Urban Wage Premium," The Review of Economic Studies, 74, 477-506. 
Gould, E. D., V. LAVY, AND M. D. PASerman (2004): “Immigrating to Opportunity: Estimating the Effect of School Quality Using a Natural Experiment on Ethiopians in Israel," The Quarterly Journal of Economics, 119, 489-526.

Greenstone, M., R. HornbecK, And E. Moretti (2010): “Identifying agglomeration spillovers: Evidence from winners and losers of large plant openings," Journal of Political Economy, 118, 536-598.

Grujovic, A. (2018): “Tasks, Cities and Urban Wage Premia,” Working Paper.

Heblich, S., S. J. Redding, AND D. M. StURm (2018): "The making of the modern metropolis: evidence from London," Tech. rep., National Bureau of Economic Research.

Imberman, S. A., A. D. Kugler, AND B. I. SACERdote (2012): “Katrina's Children: Evidence on the Structure of Peer Effects from Hurricane Evacuees," The American Economic Review, 102, 2048-2082.

KOK, S. (2014): “Town and City Jobs: How your Job is Different in Another Location," Regional Science and Urban Economics, 49, 58-67.

Lagakos, D., B. Moll, T. Porzio, N. Qian, And T. Schoellman (2018): “Life Cycle Wage Growth Across Countries," Journal of Political Economy, 126, 797-849.

LagaKos, D. And M. E. Waugh (2013): "Selection, Agriculture, and Cross-country Productivity Differences," American Economic Review, 103, $948-80$.

Lindenlaub, I. (2017): "Sorting Multidimensional Types: Theory and Application," The Review of Economic Studies, 84, 718-789. 
LUND, C. G. AND R. M. VeJLIN (2015): "Documenting and Improving the Hourly Wage Measure in the Danish IDA Database," The Danish Journal of Economics, 1, 1-35.

McKenzie, D., S. Stillman, AND J. Gibson (2010): “How Important is Selection? Experimental vs. Non-experimental Measures of the Income Gains from Migration," Journal of the European Economic Association, 8, 913-945.

Mion, G. AND P. NATiCCHIONI (2009): "The Spatial Sorting and Matching of Skills and Firms," Canadian Journal of Economics/Revue canadienne d'économique, 42, 28-55.

Papageorgiou, T. (2017): “Worker Sorting and Agglomeration Economies," Working Paper.

PATRICK, C. (2016): "Identifying the local economic development effects of million dollar facilities," Economic Inquiry, 54, 1737-1762.

Peters, M. (2019): “Market Size and Spatial Growth - Evidence from Germany's Post-War Population Expulsions," .

RedDiNG, S. J. (2016): “Goods Trade, Factor Mobility and Welfare," Journal of International Economics, 101, 148-167.

RedDing, S. J. AND D. M. StURM (2008): “The costs of remoteness: Evidence from German division and reunification," American Economic Review, 98, 1766-97.

RoвACK, J. (1982): “Wages, Rents, and the Quality of Life," Journal of Political Economy, 90, 1257-1278.

Rosen, S. (1979): "Wage-based Indexes of Urban Quality of Life," Current Issues in Urban Economics. 
Rosenthal, S. S. And W. C. Strange (2004): "Evidence on the Nature and Sources of Agglomeration Economies," Handbook of Regional and Urban Economics, 4, 2119-2171.

ShoAG, D. AND N. CAROllo (2020): “The Causal Effect of Place: Evidence from Japanese-American Internment," Harvard mimeo.

Tolbert, C. M. AND M. Sizer (1996): “US Commuting Zones and Labor Market Areas: A 1990 Update," ERS Staff Paper.

WheEler, C. H. (2006): "Cities and the Growth of Wages Among Young Workers: Evidence from the NLSY," Journal of Urban Economics, 60, 162184.

YounG, A. (2013): "Inequality, the Urban-Rural Gap, and Migration," The Quarterly Journal of Economics, 128, 1727-1785. 


\section{APPENDiX}

This Appendix contains additional materials and supporting evidence for the findings in the main body of the paper. The Online Appendix presents further details on the data and extensive robustness checks.

\section{Educational Take-Up}

In this section, we test whether refugees initially assigned to Copenhagen take-up more years of education than refugees assigned elsewhere. Column 1 of Table A.1 shows the result of a t-test of mean differences in educational take-up after assignment between the two assignment groups for the High Education sample of refugees. The second column repeats this exercise for the low education sample. In both cases, differences in take-up across areas are minimal, equivalent to about an extra month of schooling in the full sample. As a result, we must conclude that differences in educational takeup across assignment regions are not driving the dynamic treatment effects identified in Section 3.1.

\section{Parallel Wage Trends}

In this section, we study aggregate wage growth trends across our assignment regions. If aggregate developments were behind the return to big city experience, we would expect to see faster wage growth among all Danes in Copenhagen than in the rest of the country. In Figure A.1, we plot the average hourly wages earned by all working Danes, from 1986 to 2010, in the two assignment regions. The Copenhagen premium is quite stable in the aggregate, averaging 7 log points between 1986 and 2010. Most importantly, we do not observe a systematic divergence between hourly wages in Copenhagen versus Non-Copenhagen for Danes. We infer that Copen- 
hagen is not on a steeper overall growth path than the rest of the country and that aggregate wage trends across the two regions are not driving the return to big city experience we uncover.

\section{Balancing Tests for Education}

The council officers assigning refugees to municipalities did not observe refugees' education levels. We test for significant differences in years of education between refugees assigned to Copenhagen and non-Copenhagen. We regress years of schooling on a Copenhagen assignment dummy and assignment controls. Table A.2 presents the result. ${ }^{36}$ After accounting for the information available to the council officers, we find a statistically significant difference of 0.16 years of educational attainment between assignment groups. An average difference of two months of accumulated education between assignment regions is economically insignificant. To add further caution, throughout the paper, we study wage growth differences across assignment regions within education groups. Finally, we emphasize that Damm and Dustmann (2014) have conducted extensive balancing tests across subunits of our assignment regions, concluding that assignment is random conditional on the assignment controls we include throughout.

\section{Treatment Effect on Employment Rates}

In this section, we assess the effect of assignment to Copenhagen on employment rates for refugees participating in the labor force. In Table A.3, we regress an indicator for being employed on the assignment variables, and 3-year dummy bins for time spent in Denmark. We restrict the sample

\footnotetext{
${ }^{36}$ The sample used consists only of refugees without missing information when they first appear in the data set. There are more such refugees than the $19 \%$ of refugees without any educational information from Table 1. We test and reject the possibility that the fraction of refugees for whom education information is missing differs between Copenhagen and non-Copenhagen.
} 
to those who work for at least one year in our data.

In the first column, we report the results for the High Education sample in the second for the Low Education Sample. Controlling for the assignment relevant characteristics, and conditional on joining the labor force, employment rates are about $1 \%$ higher among refugees initially assigned to Copenhagen. These differences are barely significant statistically and appear minor economically.

For the High Education sample, we interact placement in Copenhagen with the years in Denmark bins, to understand the small effect estimated in Table A.3. Figure A.2 reports the estimated coefficients. For most years, the estimated coefficients are not significantly different from zero, suggesting that selection out of employment does not interact systematically with the initial assignment.

\section{Effects of Ethnic Enclaves}

Damm and Dustmann (2014) reports that before the Danish dispersal policy, immigrants and refugees overwhelmingly clustered in Copenhagen and the other larger cities. In this section, we investigate whether the larger presence of other refugees from one's country in certain municipalities can explain part of the estimated treatment effect. We re-estimate our main specification in Table A.4, including a control for the number of co-nationals of each refugee residing in their municipality of assignment in the year of assignment. The estimates for the dynamic treatment effect in Table A.4 are very similar to those reported in Table $2 .{ }^{37}$ Ethnic enclaves do not appear to be an important explanation for the differential wage-experience profiles we identified across assignment regions.

\footnotetext{
${ }^{37}$ We also re-estimated these regressions with the ethnic stock in each year as a control, instead of year of arrival, addressing concerns that refugees could sort into ethnic enclaves over time, and that this might assist them with employment opportunities. The results, available on request from the authors, are almost identical to those in Table A.4.
} 


\section{Hours Worked}

In this section, we investigate the treatment effect of assignment to the city on hours worked, conditional on working. Figure A.3 shows average hours worked conditionally on working that year, by assignment region and years in Denmark. Refugees in the High Education sample assigned to Copenhagen initially work fewer hours before catching up to those assigned outside Copenhagen. This catch-up accords with our finding that there is a static negative earnings premium from being assigned to Copenhagen (see Table 2 in the paper).

\section{Figure A.1: Wage Growth AmONG All Danes IN COPENHAGEN AND NON-COPENHAGEN}

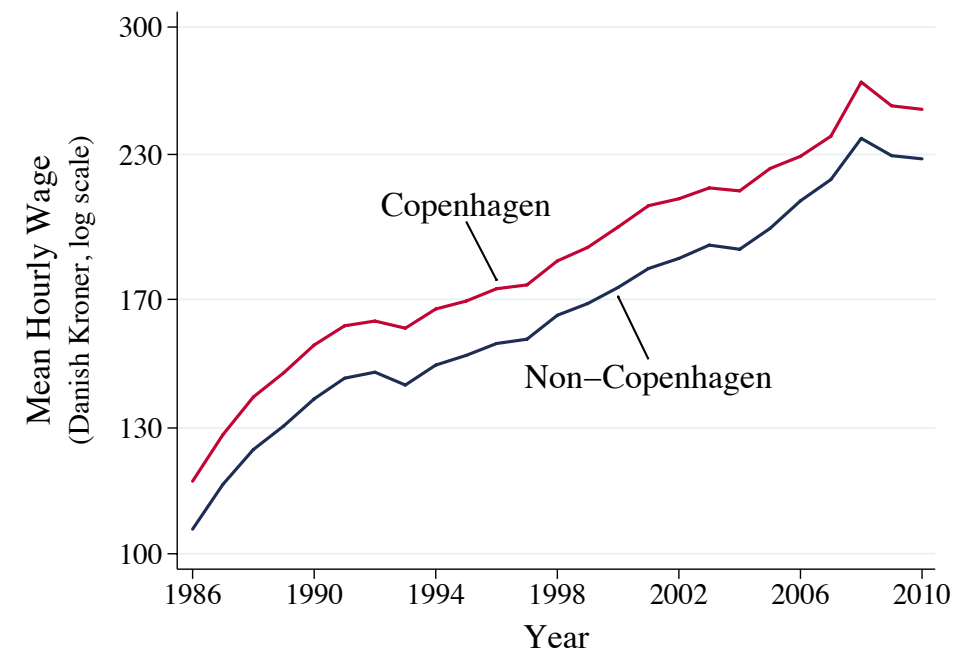

Notes: The sample underlying this figure includes all male Danes between 19 and 55 years of age. The definition of the two assignment regions, Copenhagen and non-Copenhagen, corresponds to the regions constructed in Section 2.3. Log mean hourly wage is the log of the average hourly wage of an individual in a given year and a given region in Denmark. 


\section{FiguRE A.2: NON-PARAMETRIC EMPLOYMENT RATE DIFFERENCES BETWEEN ASSIGNMENT GROUPS}

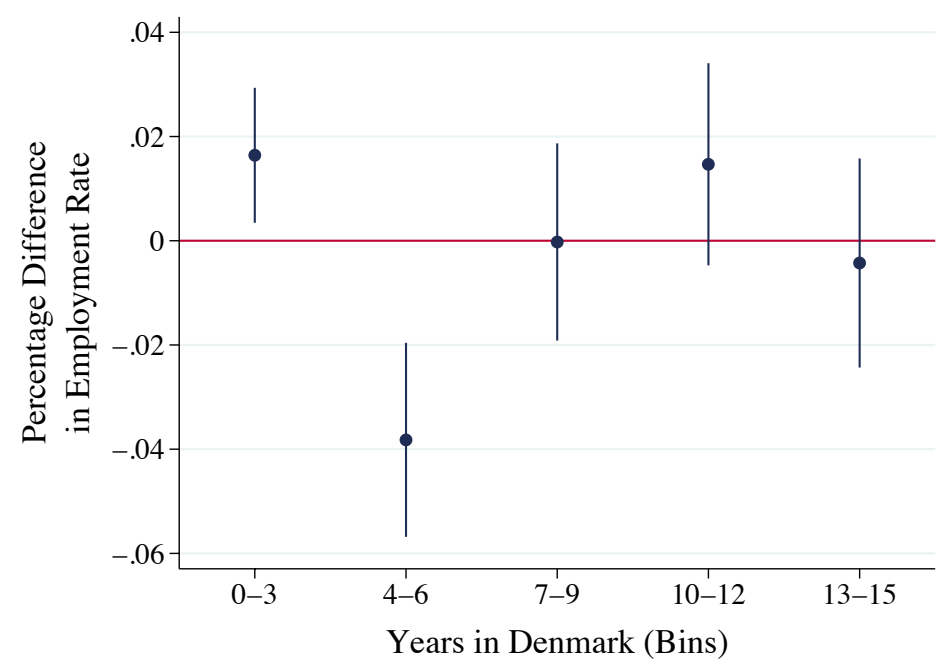

Notes: The sample underlying this table includes men between the ages of 19 and 55 who arrived in Denmark from Lebanon, Iran, Iraq, Somalia, Sri Lanka, Vietnam, Afghanistan, and Ethiopia between 1986 and 1998 with at least a high school diploma. The definition of the two assignment regions, Copenhagen and non-Copenhagen, corresponds to the regions constructed in Section 2.3. We regress an indicator variable taking the value 1 if the individual is in paid employment in a given year on assignment controls, 3-year experience bins, and 3-years experience bins interacted with a dummy variable that takes the value 1 if a refugee is initially assigned to Copenhagen. The figure plots the coefficients on the interaction between initial placement and experience bins for the various bins. Assignment controls are age at arrival, number of children at arrival, and marital status at arrival. Nationality and cohort fixed effects are also included. Cohort fixed effects control for year of arrival in Denmark. We also include nationality fixed effects. $95 \%$ confidence bounds shown in blue. 


\section{Figure A.3: MEAN YeARly HOURS Worked by EDUCATION AT ARRIVAL AND ASSIGNMENT REGION}

(A) At LeAst High SCHOOL AT

ARRIVAL

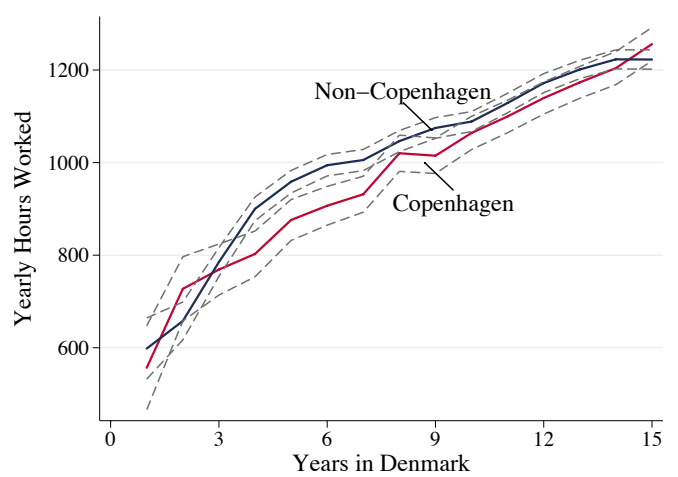

(B) LESS THAN HigH SCHOOL AT ARRIVAL

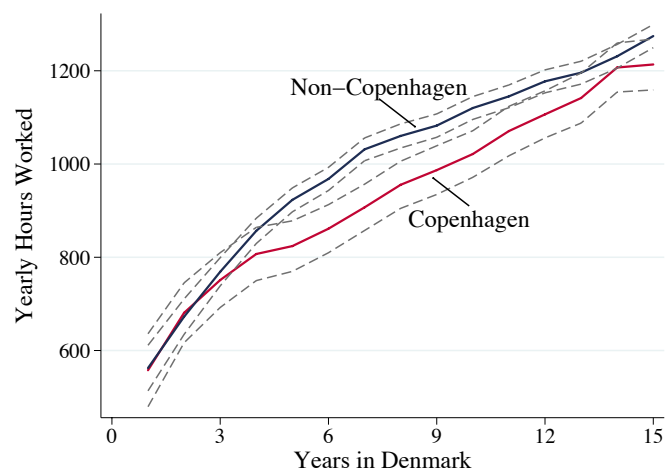

Notes: The sample underlying this table includes men between the ages of 19 and 55 who arrived in Denmark from Lebanon, Iran, Iraq, Somalia, Sri Lanka, Vietnam, Afghanistan, and Ethiopia between 1986 and 1998. The definition of the two assignment regions, Copenhagen and non-Copenhagen, corresponds to the regions constructed in Section 2.3. Years in Denmark is defined as the time since asylum was granted and the refugee started appearing in the labor market data. Average hours worked are taken across all observations in the sample, conditional on employment. Figure A.3a shows average hours worked per year for all refugees with at least high school education and conditional on a given amount of years spent in Denmark. Years in Denmark is defined as the time since asylum was granted and the refugee started appearing in the labor market data. Figure A.3b shows average hours worked per year for all refugees with less than high school education and conditional on a given amount of years spent in Denmark. 
TABle A.1: T-TeSt of DifFERENCES IN TAKE-UP OF ADDITIONAL YEARS OF EDUCATION

\begin{tabular}{lcc}
\hline \hline Sample & $\begin{array}{c}\text { High } \\
\text { Education }\end{array}$ & $\begin{array}{c}\text { Low } \\
\text { Education }\end{array}$ \\
\hline \hline Years of Additional Education & $\begin{array}{c}0.0772^{*} \\
(0.0309)\end{array}$ & $\begin{array}{c}0.0942^{* *} \\
(0.0309)\end{array}$ \\
& & \\
No Take-Up of Additional Education & $-0.0171^{*}$ & $-0.0246^{* *}$ \\
& $(0.00720)$ & $(0.00750)$ \\
Less than Two Years of Additional Education & 0.00584 & $0.0114^{*}$ \\
& $(0.00524)$ & $(0.00465)$ \\
Two to Four Years of Additional Education & 0.00400 & 0.00381 \\
& $(0.00364)$ & $(0.00479)$ \\
Four to Six Years of Additional Education & 0.00726 & $0.00937^{*}$ \\
& $(0.00408)$ & $(0.00397)$ \\
\hline Observations & 11,812 & 7,386 \\
\hline \hline
\end{tabular}

Notes: The sample underlying this table includes men between the ages of 19 and 55 who arrived in Denmark from Lebanon, Iran, Iraq, Somalia, Sri Lanka, Vietnam, Afghanistan, and Ethiopia between 1986 and 1998. The definition of the two assignment regions, Copenhagen and non-Copenhagen, corresponds to the regions constructed in Section 2.3. Years of Additional Education is the years of additional education at the latest observation of an individual. All other variables are coded as an indicator of whether the individual took up a certain number of years of education. Column 1 uses the full sample. Column 2 uses the subsample with refugees with at least a high school diploma. Standard errors in parentheses. ${ }^{* * *}$ indicates significance at the 1 percent level, ${ }^{* *}$ indicates significance at the 5 percent level, * indicates significance at the 10 percent level. 


\section{TAble A.2: Regression of Initial Years of Education on AsSign- MENT VARIABLES}

\begin{tabular}{|c|c|c|c|}
\hline \multirow[b]{2}{*}{ Sample } & \multicolumn{3}{|c|}{ Years of Education at Arrival } \\
\hline & Full & $\begin{array}{l}\text { High } \\
\text { Education }\end{array}$ & $\begin{array}{l}\text { Low } \\
\text { Education }\end{array}$ \\
\hline Initial Assignment to Copenhagen & $\begin{array}{c}0.164^{* * *} \\
(0.0491)\end{array}$ & $\begin{array}{c}0.0980 \\
(0.0571)\end{array}$ & $\begin{array}{c}0.0245 \\
(0.0454)\end{array}$ \\
\hline Assignment Controls & Yes & Yes & Yes \\
\hline Nationality FE & Yes & Yes & Yes \\
\hline Cohort FE & Yes & Yes & Yes \\
\hline R-squared & 0.171 & 0.080 & 0.061 \\
\hline Observations & 11,812 & 7,386 & 4,426 \\
\hline
\end{tabular}

Notes: The sample underlying this table includes men between the ages of 19 and 55 who arrived in Denmark from Lebanon, Iran, Iraq, Somalia, Sri Lanka, Vietnam, Afghanistan, and Ethiopia between 1986 and 1998. The definition of the two assignment regions, Copenhagen and non-Copenhagen, corresponds to the regions constructed in Section 2.3. The dependent variable in all columns is years of education at arrival. Column 1 uses the full sample, Column 2 is restricted to refugees with at least a high school diploma, and Column 3 consists of refugees with less than a high school diploma. Refugees with missing education information are dropped from the regression. Standard errors in parentheses. ${ }^{* * *}$ indicates significance at the 1 percent level, ${ }^{* *}$ indicates significance at the 5 percent level, * indicates significance at the 10 percent level. 


\section{TABle A.3: EMPloyment RATES By INITIAL ASSIGNMENT}

\begin{tabular}{lcc}
\hline \hline & \multicolumn{2}{c}{ Employment Rate } \\
\cline { 2 - 3 } Sample & $\begin{array}{c}\text { High } \\
\text { Education }\end{array}$ & $\begin{array}{c}\text { Low } \\
\text { Education }\end{array}$ \\
\hline Initial Assignment to Copenhagen & $0.00992^{*}$ & $0.0125^{*}$ \\
& $(0.00388)$ & $(0.00544)$ \\
$3 \leq$ Years in Denmark $<6$ & $0.252^{* * *}$ & $0.231^{* * *}$ \\
& $(0.00411)$ & $(0.00488)$ \\
$6 \leq$ Years in Denmark $<9$ & $0.378^{* * *}$ & $0.318^{* * *}$ \\
& $(0.00418)$ & $(0.00501)$ \\
$9 \leq$ Years in Denmark $<12$ & $0.492^{* * *}$ & $0.396^{* * *}$ \\
& $(0.00429)$ & $(0.00519)$ \\
$12 \leq$ Years in Denmark $<15$ & $0.575^{* * *}$ & $0.466^{* * *}$ \\
& $(0.00445)$ & $(0.00544)$ \\
\hline Assignment Controls & Yes & Yes \\
Nationality FE & Yes & Yes \\
Cohort FE & Yes & Yes \\
R-squared & 0.266 & 0.246 \\
Observations & 97,009 & 69,295 \\
\hline \hline
\end{tabular}

Notes: The full sample underlying this table includes men between the ages of 19 and 55 who arrived in Denmark from Lebanon, Iran, Iraq, Somalia, Sri Lanka, Vietnam, Afghanistan, and Ethiopia between 1986 and 1998. The definition of the two assignment regions, Copenhagen and non-Copenhagen, corresponds to the regions constructed in Section 2.3. The dependent variable in both columns is an indicator variable taking the value 1 if the individual is in paid employment in a given year. Column 1 uses the subsample of all refugees with at least a high school diploma and column 2 those without a high school diploma. Years in Denmark is years since arrival in Denmark, grouped into three-year bins. Assignment controls are age at arrival, number of children at arrival, and marital status at arrival. Cohort fixed effects control for year of arrival in Denmark. Standard errors in parentheses. ${ }^{* * *}$ indicates significant at the 1 percent level, ${ }^{* *}$ indicates significant at the 5 percent level, * indicates significant at the 10 percent level. 


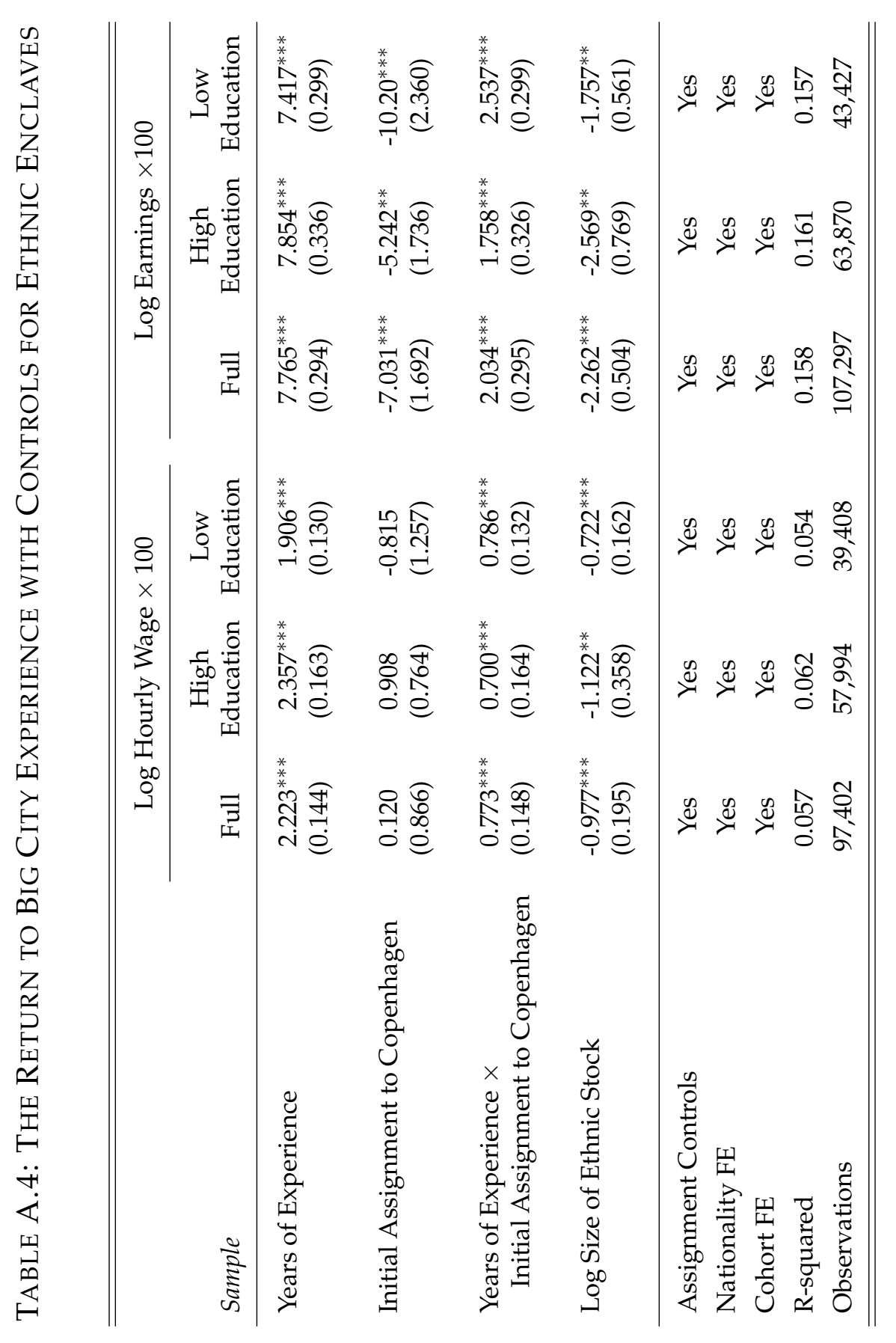

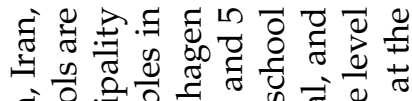

5:

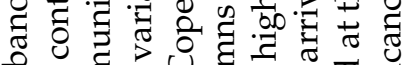

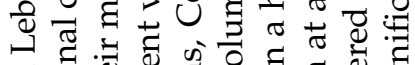

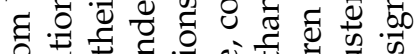

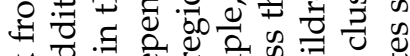

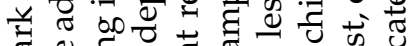

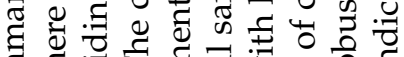
द्व cis 45 क

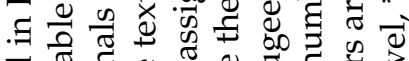

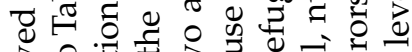

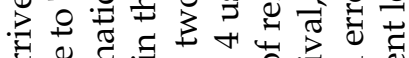
당

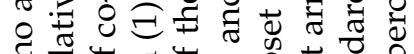
उ $\frac{\sigma}{2}$ पे

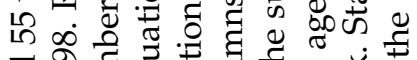

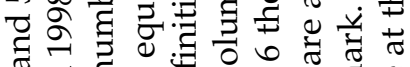
大 चै वे च च 0 \% \% 용 क्ष छ

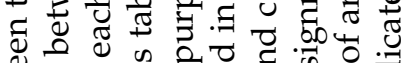

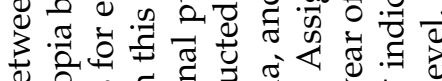

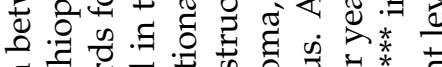

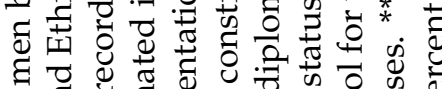
द्वे क्षै

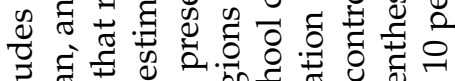

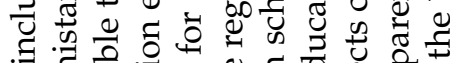

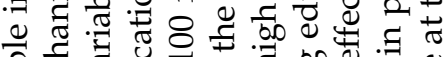

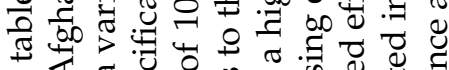

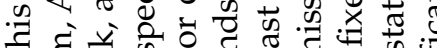

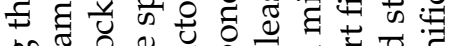

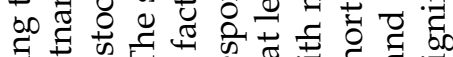
s.

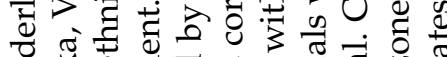

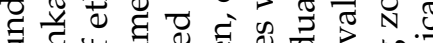
ร च च

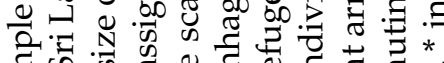

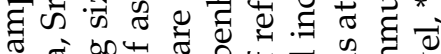
कू.

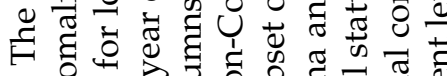

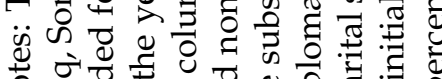

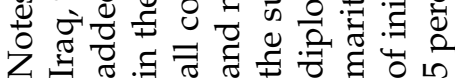

